$700 \mathrm{ml}$ per day in patients with gall stones has been observed. ${ }^{1}$ Drinking $500 \mathrm{ml}$ of tap water causes gall-bladder emptying and opacification of the common bile duct. ${ }^{1}$ I have observed in normal subjects a mean rise of $3.125 \mathrm{mmol} / 1$ in total serum bile acids 30 minutes after they have drunk $500 \mathrm{ml}$ of tap water. In cholecystectomised patients the fasting basal mean value for total serum bile acids was $11 \mathrm{mmol} /$ and the value after drinking $500 \mathrm{ml}$ of tap water was $40 \mathrm{mmol} / 1$ (unpublished personal observations).

The rise in serum bile acids after drinking water is due to gall-bladder emptying, intestinal absorption, and hepatic uptake. To increase the meal frequency is not practicable often, and it may cause an increase in weight. However, drinking water may be advised freely as it will not alter the nutritional value of the daily diet and it is easy to use. Water may cause an increase in synthesis of bile acids, which may partly explain the marked rise in total serum bile acids seen in the cholecystectomised patient after drinking water.

Drinking water at regular intervals in sufficient quantity may help in preventing gall-stone formation by decreasing the stay time and concentration of bile in the gall bladder and possibly by an increase in bile acid synthesis in cholecystectomised patients.

M V MATH

University Department of Medicine II

Singapore General Hospital,

Singapore 0316

Math MV, Rampal PM, Faure XR, Delmont JP. Singapore Medical fournal (in press).

SIR,-In their report on overnight fasting and gall-stone formation Dr J P Capron and others (28 November, p 1435) mentioned the possibility that consumption of breakfast may become more regular and substantial with aging. We can confirm this possibility from a study of a group of 772 persons (teaching staff and students of London University).

Replies to a questionnaire revealed that $34 \%$ of those aged 17-20 regularly omitted breakfast (they had nothing more than a cup of tea or coffee five or seven days a week), a proportion that fell steadily with increasing age $\left(26^{\circ}\right.$ ' at 21-30 and $31-44,11 \%$ at 45-59), until at 60 and over only $10 \cdot 7 \%$ omitted their breakfast. The association between age and breakfast habits was highly significant $(p<0.0001)$. Moreover, it has been reported from several countries that about $25 \%$ of schoolchildren over the age of about 10 years regularly omit breakfast. ${ }^{1}$

Dr Capron and his colleagues in attempting to explain these findings on gall-stone formation mentioned the possibility that their older patients may when younger have had different breakfast habits. We have been unable to find any evidence in the literature to indicate whether the habit of omitting breakfast has become commoner than it was a generation ago or whether aging as such causes the change.

There could be a physiological difference between breakfast eaters and non-eaters since there appear to be many persons who refuse to eat breakfast even when it is presented to them at what is to them an early hour, but do so later on arrival at work or at a nearby restaurant and also eat breakfast at the weekend at a later hour. We attempted to relate this to a self-applied questionnaire designed to measure what is termed "morningness" and "eveningness,"' but were unable to classify our 772 subjects into sufficiently distinct "morning" and "evening" types-most of them were in an intermediate category.

A E BENDER

NIGEL DICKIE

Department of Food Science and Nutrition, Queen Elizabeth College, London W8 7AH

' Bender AE. Proc Nutr Soc 1974;33:45-50.

2 Horne JA, Ostberg O. Int $\mathcal{F}$ Chronobiol 1976;4:97-110.

\section{Highly selective vagotomy}

SIR,-Mr J R Salaman and his colleagues have produced a timely addition to the literature concerning highly selective vagotomy (28 November, $p$ 1438) by reminding us how prevalent dyspeptic symptoms can be in a "normal" population. The late incidence of symptoms and recurrence after this operation is uncertain. In a study still to be reported in detail $^{1}$ we have shown that most patients allocated to Visick grades 3 and 4 after highly selective vagotomy are nevertheless apparently satisfied with the outcome of surgery compared with their preoperative state.

Although we share the authors' conclusions on the limitations of Visick grading, the paper contains an error. They quote a recurrence rate of $3.3 \%$, but as they were able to review only 66 of their 91 patients the recurrence rate in their series is in fact $3 / 66=4.5 \%$.

Alan G Fraser P W Brunt
Norman A Matheson Aberdeen Royal Infirmary

Aberdeen AB9 2ZB

' Fraser AG, Brunt PW, Matheson NA. Br f Surg $1981 ; 68: 804$.

\section{Diagnosis of jaundice}

SIR,-We agree with Professor Ian A D Bouchier's statement (14 November, p 1282) that standard "liver function" tests (plasma albumin and bilirubin concentrations, aminotransferase and alkaline phosphatase activities and coagulation tests) are usually adequate for the investigation of most patients suspected of having liver disease and that serum bile acid measurements do not help in the differential diagnosis of patients with cholestatic jaundice, confirmed by using these routine tests. However, standard tests of liver function do not leave every problem unresolved, and we have found serum bile acid estimation to be useful in at least two situations.

Patients with mild or well-compensated liver disease may have no clinical evidence of the underlying hepatic disorder, and plasma bilirubin and liver function as assessed by other routine tests may be so slightly deranged as to leave the diagnosis in doubt. Our expierence so far is that patients with only minor degrees of hyperbilirubinaemia due to liver disease have clearly and unequivocally increased serum bile acid concentration. ${ }^{1}$

The corollary of this lies in the diagnosis of Gilbert's syndrome. Gilbert's syndrome is usually diagnosed in patients who have unconjugated hyperbilirubinaemia in the presence of normal plasma aminotransferase and alkaline phosphatase activities and plasma albumin concentration and no evidence of haemolysis. In addition, the diagnosis may be confirmed by a period of fasting or alternatively a nico- tinic acid test may be used. We have found that patients with Gilbert's syndrome have normal serum bile acid concentrations ${ }^{2}$; and their measurement therefore offers a simple alternative to tests based on caloric restriction or nicotinic acid, which are both more complicated and more unpleasant for the patient.

These uses depend on the fact that serum bile acid measurement is a sensitive test of liver function, which might be expected since the liver has to transport $30 \mathrm{~g}$ of bile acid daily by comparison with only $250 \mathrm{mg}$ of bilirubin, which is a molecule of similar size. We have shown that measurements of serum bile acids provide a sensitive and specific index of liver dysfunction ${ }^{12}$ and this has also been found by other investigators. ${ }^{34}$ We disagree, therefore, with Professor Bouchier's statement that the estimation of serum bile acids in the jaundiced patient has not proved to be diagnostically useful.

G J BECKETT

I W PERCY-ROBB J G DOUgLas

N D C Finlayson

\section{University Department of Clinical
Chemistry and Gastrointestinal \\ and Liver Service, \\ Royal Infirmary,
Edinburgh EH3 9 YW}

${ }^{1}$ Douglas JG, Beckett GJ, Nimmo IA, Finlayson NDC, Percy-Robb IW. Gut 1981;22:141-8.

${ }^{2}$ Douglas JG. Beckett GJ, Nimmo IA, Finlayson NDC, Percy-Robb IW. Eur $\mathcal{f}$ Clin Invest (in press). 292-3. Fausa O, Gjone E. Scand $\mathcal{f}$ Gastroenterol 1976;11:
537-43.

\section{Microbiology of pyogenic liver abscess}

SIR,-Our attention has been drawn to the paper by Dr J C Moore-Gillon and others (26 September, p 819), which suggests that among others we may have mistaken Streptococcus milleri (or microaerophilic streptococci) for anaerobic streptococci in our report of 16 patients with liver abscesses, where we emphasised the importance of anaerobic pathogens. $^{1}$

Since 1974 at the Royal Free Hospital streptococci have been confirmed as strict anaerobes by their sensitivity to metronidazole as well as their inability to grow in air or in a carbon dioxide-enriched atmosphere. This has been the standard practice in many microbiology laboratories both in Britain and in the United States for some years and certainly included that of Sabbaj et $a l^{2}{ }^{2}$ who certainly did not confuse the terms microaerophilic and anaerobic in their paper; they merely grouped streptococci of both kinds together when referring to primary isolation techniques.

Dr Moore-Gillon and others are correct when they say that "careful laboratory technique" is "necessary for the recovery of fastidious organisms." Str milleri is certainly no more fastidious than are peptostreptococci or other strict anaerobes. It is also very common to isolate mixtures of pathogens from intra-abdominal abscesses of all kinds, and these often include anaerobes. It is interesting therefore that Dr Moore-Gillon and his colleagues are the only authors to report so many pure growths of Str milleri from liver abscess patients. This may be related to the total absence of data about antibiotic therapy in their patients, even though it was a "prospective" study.

Antimicrobial agents given prior to drainage 